\title{
Peatland vascular plant functional types affect dissolved organic matter chemistry
}

\author{
Bjorn J. M. Robroek (iD • Remy J. H. Albrecht • \\ Samuel Hamard • Adrian Pulgarin • Luca Bragazza • \\ Alexandre Buttler • Vincent EJ Jassey
}

Received: 31 August 2015 / Accepted: 12 October 2015 / Published online: 15 October 2015

(C) Springer International Publishing Switzerland 2015

\begin{abstract}
Background and aims Northern peatlands are large repositories of carbon. Peatland vascular plant community composition has been functionally associated to a set of biogeochemical processes such as carbon cycling. Yet, we do not fully understand to what extent vascular plant functional types (PFTs) affect the quality of dissolved
\end{abstract}

Responsible Editor: Elizabeth M. Baggs.

B. J. M. Robroek $(\bowtie) \cdot$ R. J. H. Albrecht • S. Hamard • A. Pulgarin · L. Bragazza · A. Buttler · V. E. Jassey School of Architecture, Civil and Environmental Engineering (ENAC), Laboratory of Ecological Systems (ECOS), École Polytechnique Fédérale de Lausanne (EPFL), Bâtiment GR, Station 2, -1015 Lausanne, CH, Switzerland e-mail: bjorn.robroek@epfl.ch

B. J. M. Robroek · S. Hamard · A. Pulgarin · L. Bragazza •

A. Buttler · V. E. Jassey

WSL - Swiss Federal Institute for Forest, Snow and Landscape Research, Site Lausanne, Station 2, Case postale 96, CH-1015 Lausanne, Switzerland

S. Hamard

Département de Géosciences, Ecole Normale Supérieure de Paris, 24 Rue Lhomond, 575231 Paris CEDEX, France

L. Bragazza

Department of Life Science and Biotechnologies, University of Ferrara, Corso Ercole I d'Este 32, I-44121 Ferrara, Italy

A. Buttler

University of Franche-Comté - CNRS, UMR 6249

Chrono-environnement, 16 route de Gray, F-25030 Besançon cedex, France organic matter, and if there is any feedback on soil microbial activity.

Methods Using a longer-term plant removal experiment in a boreo-nemoral peatland in Southern Sweden, we relate the dominance of different vascular plant functional types (i.e. ericoids and graminoids) to the chemistry of the dissolved organic matter (DOM) and microbial enzymatic activities (fluorescein diacetate hydrolysis, FDA). Results Our results show that PFTs modifies the composition of DOM moieties, with a decrease of low molecular weight organic compounds after vascular plant removal. The decrease of enzymatic activity by up to $68 \%$ in the plant removal plots suggests a reduction in DOM mineralization in the absence of vascular plants.

Conclusions Our results show that plant-derived low molecular organic compounds enhance peatland microbial activity, and suggest that an increase of vascular plant cover in response to climate change can potentially destabilize the $\mathrm{OM}$ in peatlands, leading to increased carbon losses.

Keywords Dissolved organic matter chemistry . Enzymatic activity $\cdot$ FDA $\cdot$ FT-IR $\cdot$ Plant functional types · Plant-soil interactions $\cdot$ Sphagnum-dominated peatlands

\section{Introduction}

High diversity of plant species is essential to maintain ecosystem processes, and consequently, the resistance to climate change (Isbell et al. 2011; Bloor and Bardgett 2012). The rationale behind this is that species, or 
groups of species (functional types), have a unique role in the ecosystem so that any change in the composition of the plant community may alter ecosystem processes, such as the soil carbon (C) cycle (Bret-Harte et al. 2004; Fornara and Tilman 2008; Ward et al. 2009; Kuiper et al. 2014). Northern peatlands are large repositories of $C$ (Yu 2012), and are often considered to be rather robust to environmental changes (Dise 2009). Nevertheless, plant community composition in peatlands has been shown to respond to global environmental changes (Gunnarsson et al. 2002; Malmer et al. 2005). Increased nitrogen deposition, for example, leads to a replacement of the peat moss communities by vascular plants (Limpens et al. 2003; Bubier et al. 2007; Wiedermann et al. 2008; Breeuwer et al. 2010), whereas climate warming seems to promote some plant functional types (e.g. ericaceous shrubs) within the vascular plant group (Breeuwer et al. 2009; Walker et al. 2015; Buttler et al. 2015). Whilst such changes in the composition of peatland plant communities do not seem to alter the robustness of peatland $\mathrm{C}$ dynamics to environmental changes (Robroek et al. 2009), recent findings attest for an important role for plant functional types (PFTs) on plant-microbe interactions (Bragazza et al. 2015) and $\mathrm{CO}_{2}$ and $\mathrm{CH}_{4}$ dynamics (Ward et al. 2013; Robroek et al. 2015). These results suggest that a change in the composition of peatland plant communities can indeed affect $\mathrm{C}$ cycling, although a satisfying mechanistic explanation remains elusive.

Selective removal experiments of vascular PFTs in peatlands have demonstrated a direct effect on microbial community composition, whilst the effect on peat chemistry was delayed or more progressive (Robroek et al. 2015). It then seems that a shift in PFTs can initially affect nutrient cycling through differences in rhizodeposition or/ and litter leachates (De Deyn et al. 2008; Hodgkins et al. 2014). If so, pore-water chemistry should represent a sentinel of organic matter changes in peatlands in response to an alteration of dominant PFTs (Chanton et al. 2008). In order to broaden our understanding of the role of vegetation changes on the chemistry of dissolved organic matter (DOM), here we relate a long-term experimental manipulation of PFTs to the chemistry of DOM and associated microbial enzymatic activity in contrasting microhabitats (i.e lawns and hummocks) of a boreonemoral peatland in Southern Sweden. In particular, we tested if selective removal of graminoids and ericoids can be mirrored in the quality of DOM, and if such changes are associated with altered microbial activity.

\section{Material and methods}

Site characteristics and sampling design

The Store Mosse National Park, Sweden (57 $17^{\prime} 54$ N, $\left.14^{\circ} 00^{\prime} 39 \mathrm{E}\right)$, is the largest pristine peatland expanse south of Lapland, and is representative of boreonemoral peatlands in Europe. In early June 2011, 40 experimental plots $(50 \times 50 \mathrm{~cm})$ were established in lawn $(n=20)$ and hummock microhabitats $(n=20)$ characterized by homogenous vegetation (see Robroek et al. 2015 for a comparable set-up) in the Sphagnumdominated (= ombrotrophic) part of the study peatland. In June 2011, we manipulated the vascular PFT composition in both microhabitats by selectively removing (i.e. clipping) ericoids (-Eric; Erica tetralix, Vaccinium oxycoccus, Andromeda polifolia, Empetrum nigrum and Calluna vulgaris), graminoids (-Gram; Eriophorum angustifolium, E. vaginatum and Rhynchospora alba) or both PFTs, whilst a set of control plots remained intact. These manipulations led to a randomised block design, with five blocks in which all treatments were randomly distributed. Vascular plant regrowth was removed every third month, but in winter, by pulling out whole seedlings (incl. Roots). $35 \times 35 \mathrm{~cm}, 20 \mathrm{~cm}$ deep collars had been installed in all plots. These collars prevented direct lateral flow between microhabitats, and caused the experimental plots to be laterally isolated from direct influence of the surrounding matrix. The effects of root decomposition were assessed by comparing $\mathrm{CO}_{2}$ respiration rates (LI-8100; LI-COR Biosciences, Lincoln, NE, USA) after one year -when apparent effects should have been most pronounced-from the removal plots with respiration rates from comparable areas in the control plots with little or no vascular plant cover (VPC). These data indicated that an effect of plant removal on root decomposition is absent, or at least marginal, as root-decomposition-derived respiration in the treatment plots was smaller than autotrophic root respiration in the control plots (Robroek et al. 2015).

Dissolved organic matter chemistry

In April 2014, pore water samples were collected in the centre of all plots at c. $10 \mathrm{~cm}$ depth, using syringe and perforated needle. Collected water was immediately filtered at $0.45 \mu \mathrm{m}$. DOC concentrations were measured on a Skalar SANPLUS segmented flow analyser (Skalar analytical, Breda, NL). Pore water dissolved organic 
matter (DOM) was characterized by fluorescence excitation emission (EEM) and diamond attenuated total reflectance (ATR) FT-IR spectroscopy. EEM provided information the fluorescing DOM fraction (humic-like substances, lignin derivates), whilst FT-IR allowed characterization of specie DOM moieties (carboxylic, aromatic, and polysaccharide components). Fluorescence excitation emission matrices (EEMs) were obtained on a spectrofluorimeter (BioTek SynergyMX) equipped with a fluorescence 96-well microplate reader. EEMs were determined at room temperature $\left(20{ }^{\circ} \mathrm{C}\right)$, at excitation and emission band-pass slit widths of $4.5 \mathrm{~nm}$. EEMs were recorded by scanning the emission wavelength over the range 250 $450 \mathrm{~nm}$, while the excitation wavelength increased gradually from 300 to $600 \mathrm{~nm}$. EEMs were acquired in triplicates. If necessary, spectra were corrected for inner filtering using the Mirrored Cell Approach (Luciani et al. 2013). All samples were blank-corrected and the two bands corresponding to the first- and the secondorder Rayleigh scattering were detected and eliminated using a simple algorithm. For FT-IR measurements, $15 \mathrm{ml}$ of pore water was freeze-dried and the remaining pellet were placed directly on the crystal of a Frontier FT-NIR/MIR Spectrometer (PerkinElmer). Spectra were obtained in the mid-infrared range (4000$400 \mathrm{~cm}^{-1}$ ) by averaging 16 times scans per sample at $4 \mathrm{~cm}^{-1}$ resolution. The PerkinElmer Spectrum 10 software automatically corrected for potential interference by atmospheric $\mathrm{CO}_{2}$ and $\mathrm{H}_{2} \mathrm{O}$. A similar force has been applied to ensure good contact between the crystal and the sample. FT-IR provided information about characteristic chemical bonds in the DOM that can be assigned to carboxylic, aromatic, phenolic, and polysaccharide structures (Niemeyer et al. 1992; Smith 1998; Pengerud et al. 2013). Three main absorption peaks were used as indicator of peat DOM quality: 1) the $1090 \mathrm{~cm}^{-1}$ region $(\mathrm{C}-\mathrm{O}$, cellulose, carbohydrates) is associated to polysaccharides; 2) the $1630 \mathrm{~cm}^{-1}$ region is indicative of aromatic $\mathrm{C}=\mathrm{C}$ and asymmetric $\mathrm{COO}^{-}$group vibrations (lignin and other aromatics and aromatic or aliphatic carboxylates); and 3) the $2920 \mathrm{~cm}^{-1}-2850 \mathrm{~cm}^{-1}$ regions reflect C-H stretching vibrations that is assigned to unsaturated aliphatic chains. We used the ratios between the relative intensities of FT-IR absorption bands to evaluate the degree of DOM decomposition (Broder et al. 2012; Biester et al. 2014; Hodgkins et al. 2014). Whilst the spectra are generally similar between samples, the relative intensity of specific regions reveals the nature of chemical changes during humification (Hodgkins et al. 2014).

\section{FDA enzymatic activity}

We extracted enzymes from peat samples collected in the rooting zone $(5-15 \mathrm{~cm}$ depth) from all plots. Briefly, $3 \mathrm{~g}$ of fresh peat were ground in $50 \mathrm{~mL} 0.1 \mathrm{M}$ $\mathrm{CaCl}_{2}$ solution with $0.05 \%$ Tween 80 and $20 \mathrm{~g}$ polyvinylpolypyrrolidone and shaken for 90 mins on a reciprocal shaker $(150 \mathrm{rpm})$. After centrifugation $\left(10,000 \mathrm{~g}\right.$ for $5 \mathrm{~min}$ at $\left.4{ }^{\circ} \mathrm{C}\right)$, the supernatant was filtrated $(0.45 \mu \mathrm{m})$ and concentrated in a cellulose dialysis tube (10 kDa molecular mass cut-off) covered with polyethylene glycol. The concentrated enzymatic extract was recovered in $10 \mathrm{~mL}$ ( $1 / 10$ of the initial volume) phosphate buffer ( $\mathrm{pH}=5.6$; a $\mathrm{pH}$ close to field conditions) (Jassey et al. 2011b). We measured the hydrolysis of fluorescein diacetate (FDA) to estimate the overall potential microbial activity in the peat as described in Green et al. (2006). For each sample, four pseudoreplicates were incubated in microwells with $38 \mu \mathrm{L}$ of enzymatic extract and $250 \mu \mathrm{L}$ of fluorescein substrate. In addition, we performed control assays for each samples to account for enzymatic quenching; four pseudoreplicate wells were incubated with $38 \mu \mathrm{L}$ of boiled enzymatic extract $\left(3 \mathrm{~h}\right.$ at $\left.90{ }^{\circ} \mathrm{C}\right)$ and $250 \mu \mathrm{L}$ of fluorescein substrate. Micro-plates were incubated $3 \mathrm{~h}$ at $25{ }^{\circ} \mathrm{C}$ in the dark and fluorescence intensity was measured at $490 \mathrm{~nm}$ for excitation and $523 \mathrm{~nm}$ for emission (BioTek SynergyMX). Potential FDA enzymatic activity was calculated in nmol of product degraded per hour and normalized by grams of dry peat (nmol h $\mathrm{h}^{-1} \mathrm{~g}^{-1} \mathrm{~d}$.wt).

\section{Data handling and statistical analyses}

We used PARAFAC to decompose excitation and emission spectra (EEMs) into various fluorescent components, thereby reducing the interference among fluorescent components. PARAFAC is a statistical tool used to decompose a complex mixture of fluorophores into noncovarying components, without any assumptions about their spectral shape or component number. PARAFAC modelling was performed to obtain excitation and emission spectra of components that drive the EEMs. We used the core consistency diagnostic (CORCONDIA) to determine the appropriate model complexity, and thus 
the number of distinct fluorescent components (Bro and Kiers 2003). Using CORCONDIA on our samples prevented over-fitting of our model (Murphy et al. 2013). Our core consistency diagnostic scores indicated a three-component model to provide the highest spectral resolution of components. The maximum intensities are excitation/emission values of 270-380/420-490 for component 1 (C1, Fig. 1), 370-440/470-560 nm for component 2 (C2, Fig. 1), and 270/310 nm for component 3 (C3; Fig. 1). $\mathrm{C} 1$ and $\mathrm{C} 3$ are commonly attributed to humic-like substances with low (C1) and high molecular weight $(\mathrm{C} 3)$ derived from lignin and other degraded plant materials (He et al. 2011; Albrecht et al. 2015; Tfaily et al. 2015). In contrast, C2 is commonly attributed to lignin derivates (Kothawala et al. 2012). The ratio between humic-like substances to ligninderivate $(\mathrm{C} 3 / \mathrm{C} 1)$ has been selected to express the aromaticity changes in DOM. PARAFAC analyses were carried out with the Progmeef program provided by R. Redon and S. Mounier (PROTEE laboratory, Univ. Toulon, France) based on Matlab ${ }^{\mathrm{TM}}$ software. The model was run with non-negativity constraints applied to each dimension, considering that negative values of these parameters have no physical meaning.

The effects of our PFT removal treatments on DOM compound ratios, DOC and potential FDA enzyme activity were analysed by analyses of variance (ANOVA) using the aov function in R version 3.2.0 (R Core Team 2015), with microhabitat ( $\mathrm{MH}$, factor), ericoid removal (-Eric, binary variable) and graminoid removal (-Gram, binary variable) as fixed variables, nested within block. Correlations between the overall enzymatic activity and FTIR ratios were tested using generalized linear models (family $=$ Gaussian). All data were tested for normality and homogeneity of variances prior to analysis and log-transformed when necessary.

\section{Results}

Dissolved organic matter chemistry

Four years after the start of vascular PFT removal, concentrations in dissolved organic carbon (DOC) where higher in the lawn microhabitats $(22.04 \pm 0.62)$ as compared to the concentrations in the hummock microhabitats $\left(19.35 \pm 0.44 ; \mathrm{F}_{1,28}=11.5, P=0.002\right)$. Within both microhabitats, we did not observe significant differences in DOC concentrations related to the plant removal treatments. The main spectroscopic differences in lawns and hummocks due to the removal treatment of PFTs are observed in the fluorescence index from EEM and in the aliphatics to polysaccharides ratio from the FT-IR analysis. Indeed, the removal of graminoids ( - Gram) resulted in an increase of the humic to lignin ratio in both microhabitats (Fig. $2 ; \mathrm{F}_{1,24}=12.6$, $P \leq 0.01$, whilst the removal of ericoids had the tendency to increase the ratio, but only in the hummocks $\left(\mathrm{F}_{1,24}=4.0, P=0.06\right)$. On the other hand, after the removal of graminoids, also the aliphatics to polysaccharides ratio decreased, but only in hummocks (Fig. 2; microhabitat $\times-$ Gram: $F_{1,28}=11.9$, $P \leq 0.01)$. In parallel, the removal of graminoids and ericoids, separately as well as in combination, decreased the aromatics to polysaccharides ratio in hummocks (Fig. 2), although these changes were not significant (-Eric: $\mathrm{F}_{1,28}=0.7, P=0.40$; -Gram: $\mathrm{F}_{1,28}=0.4, P=0.52$ ). Both the aliphatics to polysaccharides and the aromatics to polysaccharides ratio were lower in the hummocks as compared to lawns (Fig. 2; aliphatics:polysaccharides: $\mathrm{F}_{1,28}=4.3, P \leq 0.05$; aromatics:polysaccharides: $\left.\mathrm{F}_{1,28}=21.9, P \leq 0.001\right)$. The DOM carboxylic to polysaccharides ratio did not show any trend in response to the PFT removal for both the microhabitats (Fig. 2).
Fig. 1 Results of the PARAFAC analysis with three components and 40 excitation/emission matrices (EEMs) of DOM samples
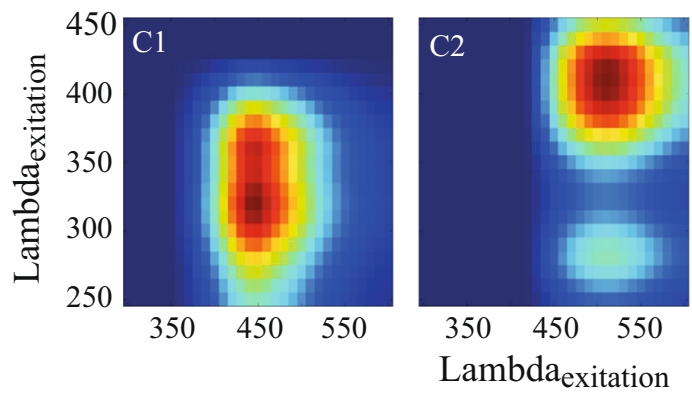


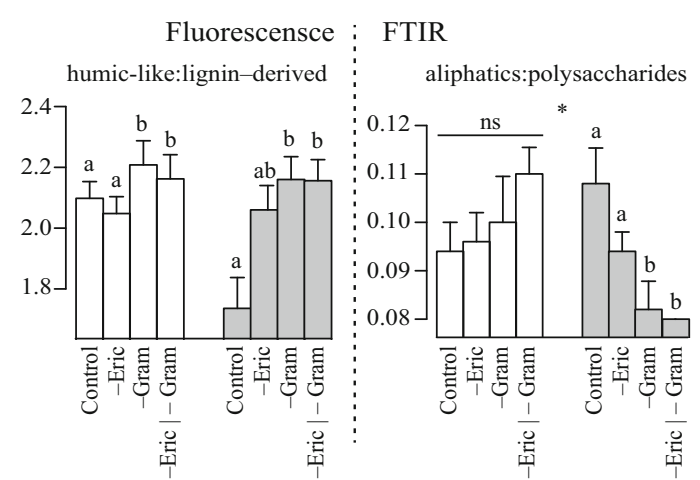

Fig. 2 Effects of vascular plant removal treatments on ratios from fluorescence and FT-IR analyses. White bars represent lawns, grey bars represent hummocks. Different letters indicate

Potential enzymatic activity

Overall, the potential enzymatic activity as expressed by the FDA was significantly higher in the lawns (Fig. 3; mean $=43.4 \mathrm{nmol} \mathrm{h}^{-1} \mathrm{~g}^{-1} \mathrm{~d}$.wt) than in hummocks (Fig. 3; mean $=13.4 \mathrm{nmol} \mathrm{h}^{-1} \mathrm{~g}^{-1}$ d.wt; $F_{1,29}=23.7$, $P \leq 0.001)$. In the lawns, vascular PFT removal did not significantly affect enzymatic activity (-Eric:
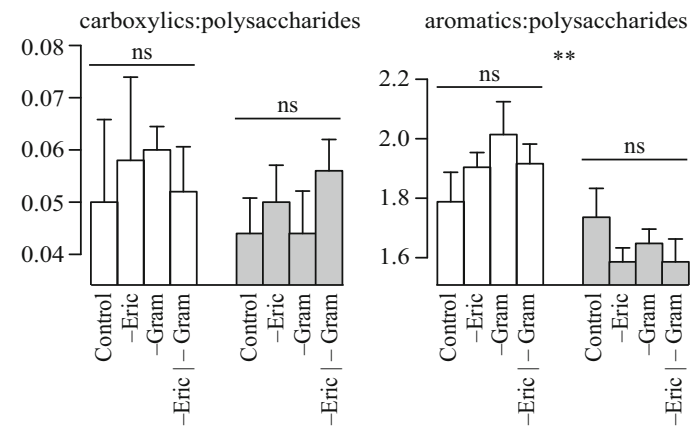

significant difference $(P \leq 0.05)$ within microhabitat; asterisks define significant differences between lawn and hummock microhabitats $(* P \leq 0.05, * * P \leq 0.01, \mathrm{~ns}=$ non-significant)

$\mathrm{F}_{1,15}=2.8, P=0.11 ;-$ Gram: $\mathrm{F}_{1,15}=1.2, P=0.29$; -Eric|-Gram: $\mathrm{F}_{1,15}=0.8, P=0.40$; Fig. 3 ), although it tended to decrease in plant removal treatments (-Eric: $-45 \%$; -Gram: $-35 \%$; -Eric|-Gram: $-49 \%$ ). In the hummocks, enzymatic activity decreased by up to $68 \%$ in the plant removal treatments (Fig. 3; -Eric: $\mathrm{F}_{1,13}=9.3, P=0.009 ;-$ Gram: $\mathrm{F}_{1,13}=14.1, P=0.002$; -Eric $\mid$-Gram: $\left.\mathrm{F}_{1,13}=11.7, P=0.005\right)$, respectively.

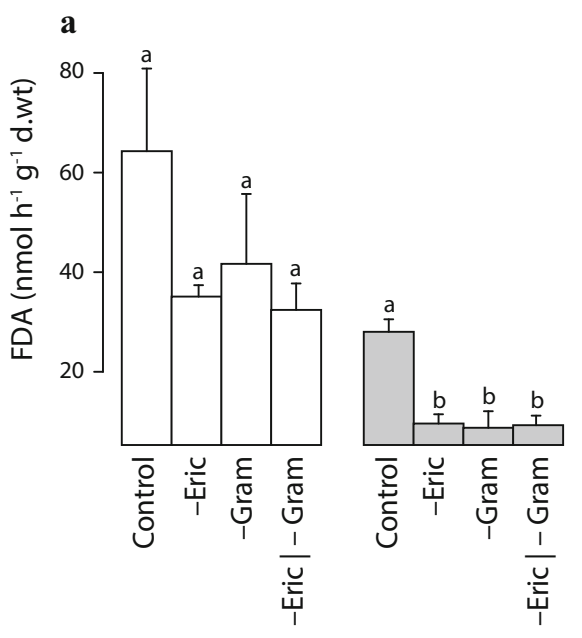

Fig. 3 Effects of vascular plant removal treatments on fluorescein diacetate activity (FDA) activity and correlations with FT-IR spectroscopic ratios for lawn (top) and hummock (bottom) pore
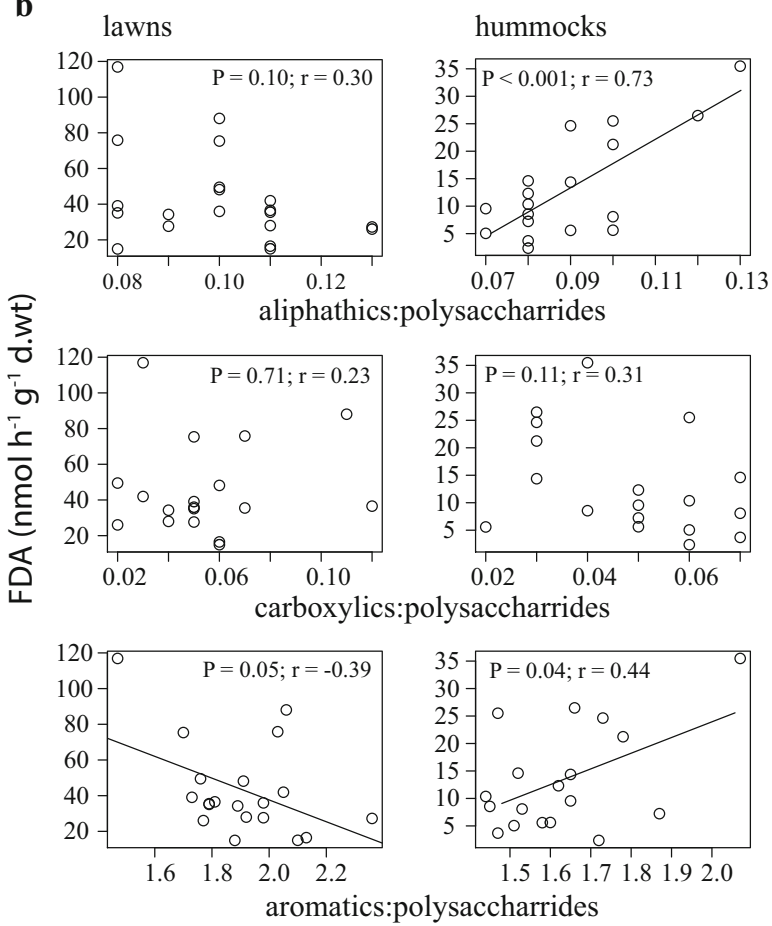

water. Different letters indicate significant differences $(P \leq 0.05)$ within microhabitat 
Regression analyses showed that the enzymatic activity in the lawns was negatively correlated with the aromatics to polysaccharides ratio $\left(R^{2}=0.16, F_{1,18}=4.5\right.$, $P=0.05$ ), whilst in the hummocks it was positively correlated with the alipathics to polysaccharides ratio as well as with the aromatics to polysaccharides ratio $\left(R^{2}=0.53, F_{1,16}=20.4, P<0.001 ; R^{2}=0.20\right.$, $F_{1,16}=5.2, P=0.04$, respectively; Fig. 3).

\section{Discussion}

Opposite to earlier findings (Robroek et al. 2014), concentrations of dissolved organic carbon (DOC) were higher in the lawn microhabitats as compared to hummock microhabitats. This anomaly may be explained by the higher values in enzymatic activity, suggesting higher microbial activity in the lawn microhabitat. Following this reasoning, and the results of studies in comparable ecosystems reporting vegetation controls on DOC concentrations and fluxes(Neff and Hooper 2002; Robroek et al. 2014; Ward et al. 2015), we would have expected DOC to differ between plant removal treatments. Our results, however, indicate no role of the plant community on DOC. Data from the same experimental plots have shown shifts in the microbial community composition under different plant communities (Robroek et al. 2015). Such shift might have led to changes in in the specific DOC moieties without affecting the total concentration. Along that line, the composition of the DOM at depth between fen and bog ecosystems has been reported to be rather different, despite the presence of similar organic matter substrate-Sphagnum peat, indicating an important role of the living vegetation on the DOM chemistry (Hodgkins et al. 2014). The removal of vascular plants in our study resulted in higher DOM humic to lignin ratios, which is likely to be due to a decrease of plant derived lignin compounds upon plant functional type removal. Interestingly, the removal of vascular plants decreased the aliphatics to polysaccharide ratio, especially in the hummocks (Fig. 2), suggesting an increase in the freshness of the DOM. These results would rule out a direct effect of plant derived labile carbon leachates, or the absence thereof, on the DOM composition. Alternatively, plant removal may have relaxed decomposition rates in the peat. Indeed, decreases in the ratios of aliphatics, aromatics and phenolics to polysaccharides generally suggests decreased peat humification
(Hodgkins et al. 2014). Two mechanisms may be responsible for this tendency: first, the absence of root exudates may decrease microbial metabolism due to reduced substrate availability; second, vascular plant removal reduces peat oxygenation associated to the rhizosphere, consequently hampering the microbial degradation of DOM. The latter mechanism can additionally explain why the removal of graminoids has the largest effect, but fails to explain why these effects are not apparent in the lawns. Indeed, graminoids, in particular Eriophorum vaginatum are recognized for their welldeveloped aerenchymatous tissues (Greenup et al. 2000) and occur mostly in wet lawns. Lawns are typically hydrological discharge areas that are more permanently anoxic compared to hummocks. The effect of rhizosphere oxygenation should therefore be more profound in lawn microhabitats, and such we would have expected the removal of vascular plants to take the largest effect in lawns. As this was not the case in our study, our data seem to suggest that the influence of vascular plants on decomposition processes, and the dissolved organic matter chemistry is restricted to aerobic microhabitats.

Interestingly, not all ratios between DOM moieties shifted with the removal of vascular plant functional types. As the concentrations of dissolved organic carbon remained unaffected, these results suggest a shift in the structure of the DOM chemical composition. Earlier, we have already shown that PFT removal was linked to a shift in the microbial community composition (Robroek et al. 2015). In addition, Hodgkins et al. (2014) link a shift in peatland vegetation to a shift in microbial pathways for methanogenesis. Although our results are not conclusive, the removal of vascular plants, and thus the lack of input of root exudates, may have resulted in the microbial community to switch to an alternative carbon source. Such shift have earlier been observed in Artic soils, where the microbial community switched to more recalcitrant sources of carbon when temperature was induced (Biasi et al. 2005; Dorrepaal et al. 2009). Essentially, these results would indicate that plant-derived labile carbons would protect the more recalcitrant substrate in the peat. Indeed, aliphatic compounds are well known to be very easy to degrade (Albrecht et al. 2008). As such, the removal of vascular plants induces a quick decrease of aliphatic compounds, thereby decreasing the aliphatic to polysaccharide ratio in the hummocks. In the lawns, the lack of oxygen inhibits microbial degradation (Fenner and Freeman 2011). On the 
whole, our results suggest an important role of vascular PFTs on the build up of DOM compounds resistant to microbial degradation, which we postulate to be mediated by plant-derived labile carbons. The absence of vascular plants could cause the microbial community to be deprived of an easy substrate (i.e. root exudates), by which more complex, recalcitrant sources of $\mathrm{C}$ need to be used, shifting the structure of the DOM.

The apparent shift in the DOM complexity largely determines its decomposability (Albrecht et al. 2008). As a consequence, the DOM fraction (i.e. after biodegradation) plays a role in the stability of peat organic matter as it is rather resistant to microbial degradation (Kalbitz 2003). Earlier, Tfaily et al. (2013) suggested that DOM in peatlands is resistant to microbial decomposition. Our observations indicate that this may only hold in oxygen deprived conditions (i.e. lawns). Indeed, anaerobic biodegradation of organic compounds is well known to be very slow as compared to aerobic biodegradation (Freeman et al. 2001). Accordingly, the effect of plant community on enzymatic activity was stronger in more aerobic hummocks as compared to more anaerobic lawns. It has been shown that FDA hydrolysis is constrained by oxygen availability and remains stable once microbes consumed all available oxygen (Ingham and Klein 1982), which is probably the case in all lawn plots. Initial plant cover in lawns is lower than in hummocks (see Robroek et al. 2015), by which the effect of plant removal may be lower in lawns. While circumstantial, these results suggests that lawn microbial communities are less dependent on plant derived labile carbon, which is underpinned by the negative relationship between enzymatic activity and the aromatics to polysaccharide ratio in these microhabitats. Importantly, however, overall potential enzymatic activity was positively correlated with the reduction of easily degradable $\mathrm{C}$ (aliphatic $\mathrm{C}$ and, to a lesser extent, aromatic $\mathrm{C}$ ). We interpret these results as evidence that microorganisms are using the metabolic energy provided by plant $\mathrm{C}$ exudates to synthetize hydrolytic enzymes (Blagodatskaya and Kuzyakov 2008; Bird et al. 2011). As microbes preferentially use these plant-derived labile $\mathrm{C}$ sources, this is expected to prime OM decomposition (Phillips et al. 2011). Although we did not measure oxidative enzymes involved in the degradation of complex molecules such as lignin, it has earlier been shown that phenoloxidase activity increased with increasing vascular plant cover in peatlands (Jassey et al. 2011a). Such increased phenoloxidase activity could have stimulated the decomposition of recalcitrant DOM, as shown for other terrestrial ecosystems (Phillips et al. 2011; Bird et al. 2011).

Vascular plant cover is likely to increase with climate warming (Elmendorf et al. 2012) with potential feedback to microbial activity in peat (Bragazza et al. 2013). Our results indicate that the composition of vascular plant community can affect the quality of DOM. Essentially, the presence of vascular plants seems to promote the degradation of DOM through providing easily $\mathrm{C}$ degradable compounds to the soil microbial community (mediated by root-exudates). Eventually, a further increase in vascular plant as induced by climate change may then result in increased OM decomposition, with an ultimate effect on the capacity of peatlands to act as $\mathrm{C}$ sinks.

Acknowledgments We are indebted to Länsstyrelsen i Jönköpings län and the staff of the Store Mosse National Park, particularly Arne Andersson, Peter Mattiasson and Martha Wageus, for granting access to the peatland (permission 521895-2011) and make use of the infrastructure of the park. Roy van Grunsven and two anonymous reviewers provided valuable comments on the scientific content. This work has been financed partially by the Swiss National Science Foundation (SPHAGNOL project; grant number 315280-14807).

\section{References}

Albrecht R, Ziarelli F, Alarcón Gutiérrez E, et al. (2008) 13C solidstate NMR assessment of decomposition pattern during cocomposting of sewage sludge and green wastes. Eur J Soil Sci 59:445-452

Albrecht R, Verrecchia E, Pfeifer HR (2015) The use of solidphase fluorescence spectroscopy in the characterisation of organic matter transformations. Talanta 134:453-459

Biasi C, Rusalimova O, Meyer H, et al. (2005) Temperaturedependent shift from labile to recalcitrant carbon sources of Arctic heterotrophs. Rapid Commun Mass Spectrom 19: 1401-1408

Biester H, Knorr KH, Schellekens J, et al. (2014) Comparison of different methods to determine the degree of peat decomposition in peat bogs. Biogeosciences 11:2691-2707

Bird JA, Herman DJ, Firestone MK (2011) Rhizosphere priming of soil organic matter by bacterial groups in a grassland soil. Soil Biol Biochem 43:718-725

Blagodatskaya E, Kuzyakov Y (2008) Mechanisms of real and apparent priming effects and their dependence on soil microbial biomass and community structure: critical review. Biol Fertil Soils 45:115-131

Bloor JMG, Bardgett RD (2012) Stability of above-ground and below-ground processes to extreme drought in model grassland ecosystems: interactions with plant species diversity and 
soil nitrogen availability. Perspect Plant Ecol, Evol Systemetics 14:193-204

Bragazza L, Parisod J, Buttler A, Bardgett RD (2013) Biogeochemical plant-soil microbe feedback in response to climate warming in peatlands. Nat Clim Chang 3:273-277

Bragazza L, Bardgett RD, Mitchell EAD, Buttler A (2015) Linking soil microbial communities to vascular plant abundance along a climate gradient. New Phytol 205:1175-1182

Breeuwer A, Robroek BJM, Limpens J, et al. (2009) Decreased summer water table depth affects peatland vegetation. Basic Appl Ecol 10:330-339

Breeuwer A, Heijmans MMPD, Robroek BJM, Berendse F (2010) Field simulation of global change: transplanting northern bog mesocosms southward. Ecosystems 13:712-726

Bret-Harte MS, García EA, Sacré VM, et al. (2004) Plant and soil responses to neighbour removal and fertilization in Alaskan tussock tundra. J Ecol 92:635-647

Bro R, Kiers HAL (2003) A new efficient method for determining the number of components in PARAFAC models. J Chemom 17:274-286

Broder T, Blodau C, Biester H, Knorr KH (2012) Peat decomposition records in three pristine ombrotrophic bogs in southern Patagonia. Biogeosciences 9:1479-1491

Bubier JL, Moore TR, Bledzki LA (2007) Effects of nutrient addition on vegetation and carbon cycling in an ombrotrophic bog. Glob Chang Biol 13:1168-1186

Buttler A, Robroek BJM, Laggoun-Défarge F, et al. (2015) Experimental warming interacts with soil moisture to discriminate plant responses in an ombrotrophic peatland. J Veg Sci 26:964-974

Chanton JP, Glaser PH, Chasar LS, et al. (2008) Radiocarbon evidence for the importance of surface vegetation on fermentation and methanogenesis in contrasting types of boreal peatlands. Glob Biogeochem Cycles 22:GB4022

De Deyn GB, Cornelissen JHC, Bardgett RD (2008) Plant functional traits and soil carbon sequestration in contrasting biomes. Ecol Lett 11:516-531

Dise NB (2009) Peatland response to global change. Science 326: $810-811$

Dorrepaal E, Toet S, RSP VL, et al. (2009) Carbon respiration from subsurface peat accelerated by climate warming in the subarctic. Nature 460:616-619

Elmendorf SC, Henry GHR, Hollister RD, et al. (2012) Global assessment of experimental climate warming on tundra vegetation: heterogeneity over space and time. Ecol Lett 15:164-175

Fenner N, Freeman C (2011) Drought-induced carbon loss in peatlands. Nat Geosci 4:895-900

Fornara DA, Tilman D (2008) Plant functional composition influences rates of soil carbon and nitrogen accumulation. J Ecol 96:314-322

Freeman C, Ostle N, Kang H (2001) An enzymic "latch" on a global carbon store. Nature 409:149

Green, Stott, Diack (2006) Assay for fluorescein diacetate hydrolytic activity: optimization for soil samples. Soil Biol Biochem 38:693-701

Greenup AL, Bradford MA, McNamara NP, et al. (2000) The role of Eriophorum vaginatum in $\mathrm{CH}_{4}$ flux from an ombrotrophic peatland. Plant Soil 227:265-272
Gunnarsson U, Malmer N, Rydin H (2002) Dynamics or constancy in Sphagnum dominated mire ecosystems? A 40-year study. Ecography 25:685-704

He X, Xi B, Wei Z, et al. (2011) Spectroscopic characterization of water extractable organic matter during composting of municipal solid waste. Chemosphere 82:541-548

Hodgkins SB, Tfaily MM, McCalley CK, et al. (2014) Changes in peat chemistry associated with permafrost thaw increase greenhouse gas production. PNAS 111:5819-5824

Ingham ER, Klein DA (1982) Relationship between fluorescein diacetate-stained hyphae and oxygen utilization, glucose utilization, and biomass of submerged fungal batch cultures. Appl Environ Microbiol 44:363-370

Isbell F, Calcagno V, Hector A, et al. (2011) High plant diversity is needed to maintain ecosystem services. Nature 477:199-202

Jassey VEJ, Chiapusio G, Gilbert D, et al. (2011a) Experimental climate effect on seasonal variability of polyphenol/ phenoloxidase interplay along a narrow fen-bog ecological gradient in Sphagnum fallax. Glob Chang Biol 17: 2945-2957

Jassey VEJ, Chiapusio G, Mitchell EAD, et al. (2011b) Fine-scale horizontal and vertical micro-distribution patterns of testate amoebae along a narrow fen/bog gradient. Microb Ecol 61: $374-385$

Kalbitz K (2003) Changes in properties of soil-derived dissolved organic matter induced by biodegradation. Soil Biol Biochem 35:1129-1142

Kothawala DN, Wachenfeldt von E, Koehler B, Tranvik LJ (2012) Selective loss and preservation of lake water dissolved organic matter fluorescence during long-term dark incubations. Sci Total Environ 433:238-246

Kuiper JJ, Mooij WM, Bragazza L, Robroek BJM (2014) Plant functional types define magnitude of drought response in peatland $\mathrm{CO}_{2}$ exchange. Ecology 95:123-131

Limpens J, Berendse F, Klees H (2003) N deposition affects N availability in interstitial water, growth of sphagnum and invasion of vascular plants in bog vegetation. New Phytol 157:339-347

Luciani X, Redon R, Mounier S (2013) How to correct inner filter effects altering $3 \mathrm{D}$ fluorescence spectra by using a mirrored cell. Chemom Intell Lab Syst 126:91-99

Malmer N, Johansson T, Olsrud M, et al. (2005) Vegetation, climatic changes and net carbon sequestration in a northScandinavian subarctic mire over 30 years. Glob Chang Biol 1:1895-1909

Murphy KR, Stedmon CA, Graeber D, Bro R (2013) Fluorescence spectroscopy and multi-way techniques. PARAFAC. Anal Methods 5:6557-6511

Neff JC, Hooper DU (2002) Vegetation and climate controls on potential $\mathrm{CO}_{2}$, DOC and DON production in northern latitude soils. Glob Chang Biol 8:872-884

Niemeyer J, Chen Y, Bollag JM (1992) Characterization of humic acids, composts, and peat by diffuse reflectance Fouriertransform infrared spectroscopy. Soil Sci Soc Am J 56:135-140

Pengerud A, Cécillon L, Johnsen LK, et al. (2013) Permafrost distribution drives soil organic matter stability in a subarctic palsa peatland. Ecosystems 16:934-947

Phillips RP, Finzi AC, Bernhardt ES (2011) Enhanced root exudation induces microbial feedbacks to $\mathrm{N}$ cycling in a pine forest under long-term $\mathrm{CO}_{2}$ fumigation. Ecol Lett 14: 187-194 
R Core Team (2015) R: A language and environment for statistical computing. R Foundation for Statistical Computing, Vienna, Austria. ISBN 3-900051-07-0, URL http://www.R-project.org/.

Robroek BJM, Schouten MGC, Limpens J, et al. (2009) Interactive effects of water table and precipitation on net $\mathrm{CO}_{2}$ assimilation of three co-occurring Sphagnum mosses differing in distribution above the water table. Glob Chang Biol 15:680-691

Robroek BJM, Wubs E, Marti M, et al. (2014) Microclimatological consequences for plant and microbial composition in sphagnumdominated peatlands. Boreal Environ Res 19:195-208

Robroek BJM, Jassey VEJ, Kox MAR, et al. (2015) Peatland vascular plant functional types affect methane dynamics by altering microbial community structure. J Ecol 103:925-934

Smith BC (1998) Infrared spectral interpretation: a systematic approach. CRC Press LLC, Boca Raton

Tfaily MM, Hamdan R, Corbett JE, et al. (2013) Investigating dissolved organic matter decomposition in northern peatlands using complimentary analytical techniques. Geochim Cosmochim Acta 112:116-129

Tfaily MM, Corbett JE, Wilson R, et al. (2015) Utilization of PARAFAC-modeled excitation-emission matrix (EEM) fluorescence spectroscopy to identify biogeochemical processing of dissolved organic matter in a northern peatland. Photochem Photobiol 91:684-695

Walker TN, Ward SE, Ostle NJ, Bardgett RD (2015) Contrasting growth responses of dominant peatland plants to warming and vegetation composition. Oecologia 178:141-151

Ward SE, Bardgett RD, McNamara NP, Ostle NJ (2009) Plant functional group identity influences short-term peatland ecosystem carbon flux: evidence from a plant removal experiment. Funct Ecol 23:454-462

Ward SE, Ostle NJ, Oakley S, et al. (2013) Warming effects on greenhouse gas fluxes in peatlands are modulated by vegetation composition. Ecol Lett 16:1285-1293

Ward SE, Orwin KH, Ostle NJ, et al. (2015) Vegetation exerts a greater control on litter decomposition than climate warming in peatlands. Ecology 96:113-123

Wiedermann MM, Gunnarsson U, Nilsson MB, et al. (2008) Can small-scale experiments predict ecosystem responses? An example from peatlands. Oikos 118:449-456

Yu ZC (2012) Northern peatland carbon stocks and dynamics: a review. Biogeosciences 9:4071-4085 